\title{
A Return to BC19: From Virtual to Real International Travel — the Road is Long
}

\author{
David L. Heymann ${ }^{*}$
}

Virtual meetings, virtual travel podcasts, and virtual family reunions - a 21st century shift forced upon us by the coronavirus disease 2019 (COVID-19) pandemic - are an urgent leap forward to a new way of working and socialising.

But the dialogue is now changing in anticipation of a shift back to the way it was before COVID-19 - to the era some are calling "Before COVID-19" or BC19. This anticipation is occurring because the epidemiology of the COVID-19 virus* has become more clearly understood - given a kickstart by the extensive research done by Chinese researchers early in the pandemic and continuing today; and because there are now an astounding number of easier to use diagnostic tests, vaccines, and therapeutics that were only a hope one year ago.

But will this shift back to BC19 benefit from what we have learned from living in the virtual world during the past year - that virtual meetings can have the hoped for outcomes, that travel podcasts can provide new thoughts and experiences, and that virtual reunions can keep families close together across long distances. Will there be a mix of virtual and real international travel in $\mathrm{BC} 19$, and will this prolong the glimpse of benefits that the decrease in international travel has brought to our environment and to our own well being (1)? Or will the pandemic have been a glitch in our usual way of life that rapidly disappears - in fact, there is an omen that this might be true.

Though it is too early to know how the shift to BC19 will finally play out, especially as variants of the COVID-19 virus continue to evolve, there is clearly a sense of great urgency to get back to international travel (2). International travel is perceived to be as important today as it has been since the establishment of the great trade routes in history including the Silk Road, the trade route that linked people and goods from the Middle East and China to the Western world. The Silk Road, and many other networks of human travel and trade, were often interrupted by pandemics - plague, cholera, and smallpox - yet they came back and continued to evolve and increase as new means of public conveyance were developed.

Yellow fever is a good recent example of how an infectious disease slowed and disrupted international travel and trade, such as in the early 20th century when yellow fever outbreaks disrupted the construction of the Panama Canal. They had become a concern for international travel within the Americas in the late 19th century when major urban outbreaks occurred where yellow fever had not been previously recorded (3). Innovation prevailed, however, and in the 1930s a yellow fever vaccine was developed that prevented its infection and transmission and all was changed (4).

Along the road to BC19, late last year Hong Kong, China and Singapore conceived a way of ensuring safer international travel between each of their massive urbanised areas - what they called a "travel bubble." But by the end of December the travel bubble had burst (5). One of the perceptions for creating the bubble appeared to be that equal risk of infection and equal detection and response capacity, along with strategic testing for COVID-19 virus, could lead to decreased risk of infection during travel and upon landing. An increase in reported infections in one of these two urban areas, however, caused a perceived imbalance in the risk and plans were abandoned. The mantra of equal risk and equal response capacity and safe travel was shown to be difficult to implement but is a goal still being sought. And as a follow up, the World Health Organization is developing a risk assessment framework to help countries estimate and compare their travel risks.

And today there are vaccines as well. Just as in the 1930s when the newly developed yellow fever vaccine led to prevention of infection and transmission and to safer international travel in the Americas, COVID-19 vaccines are giving the same hope - that international travel will again become safe, returning the world of international travel to its $\mathrm{BC} 19$ level.

\footnotetext{
"Also know as SARS-CoV-2 in some researches.
} 
In fact there is talk of "vaccine or immunity passports" and of international vaccination cards as a means of ensuring safe international travel, minimising both the risk of transmission in airports and airplanes (G).

But while vaccines provide almost complete personal protection against serious illness and death - the end point in the studies conducted for licensing - there is still not evidence as to whether these vaccines prevent infection or whether they modify infection once it has occurred. And there is not yet evidence to help understand how long the protective effect of these vaccines will last, and whether new variants of the virus will impact on protection though evidence is accumulating ( 7 ).

These answers will rapidly become available as more and more persons are vaccinated and post-vaccination surveillance and research continues. For now however, patience is the byword. We know for example that persons vaccinated against polio are protected from infection, but they can still carry wild poliovirus in the gut and transmit to others. And we also know that for some bacterial vaccines - the polysaccharide meningitis vaccine for example - nasal carriage of meningitis bacteria was possible and only rectified by innovation of a conjugate vaccine that eliminates this carriage.

Though there is some evidence that some of the COVID-19 vaccines decrease nasal carriage of COVID-19 virus from small subsets of persons studies in clinical trials, more information is required along with that about duration of the protective response.

So returning to $\mathrm{BC} 19$ for international travel is still a cautious journey - there is a need for continued understanding and innovation using the tools we have today, and the will that we can and must return in a more environmentally friendly way. But there is one caveat - and that relates to an unsubstantiated report of neighbour who recently returned on an international flight. His certification of a negative test for COVID-19 came from a template in the virtual world of the internet - not from a medically authorised laboratory.

The road is long for the return to international travel BC19 and presents many challenges along the way.

doi: $10.46234 / \mathrm{ccdcw} 2021.042$

\# Corresponding author: David L. Heymann, David.Heymann@ LSHTM.ac.uk.

Submitted: January 30, 2021; Accepted: February 01, 2021

\section{REFERENCES}

1. Belesova K, Heymann DL, Haines A. Integrating climate action for health into covid-19 recovery plans. BMJ 2020;370:m3169. http://dx.doi.org/10.1136/bmj.m3169.

2. ICAO. ICAO encourages proactive pursuit of public health corridor, travel bubble solutions. https://centreforaviation.com/members/directnews/icao-encourages-proactive-pursuit-of-public-health-corridor-travelbubble-solutions-543045. [2021-1-29].

3. Perkins E, Magill J. In the late 1800 s, devastating yellow fever epidemics forced New Orleans to confront its sanitation problem. https://www. hnoc.org/publications/first-draft/late-1800s-devastating-yellow-feverepidemics-forced-new-orleans-confront. [2021-1-29].

4. Frierson JG. The yellow fever vaccine: a history. Yale J Biol Med 2010; 83(2): 77-85. https://www.ncbi.nlm.nih.gov/pmc/articles/PMC2892770/.

5. Lee YN. Singapore and Hong Kong push back their travel bubble again, this time beyond 2020. https://www.cnbc.com/2020/12/01/singaporeand-hong-kong-push-back-their-travel-bubble-again-this-time-beyond2020.html. [2021-1-29].

6. Brown RCH, Kelly D, Wilkinson D, Savulescu J. The scientific and ethical feasibility of immunity passports. Lancet Infect Dis 2020. http://dx.doi.org/10.1016/S1473-3099(20)30766-0.

7. World Health Organization. The moderna COVID-19 (mRNA-1273) vaccine: what you need to know. https:/www.who.int/news-room/ feature-stories/detail/the-moderna-covid-19-mrna-1273-vaccine-whatyou-need-to-know. [2021-1-29].

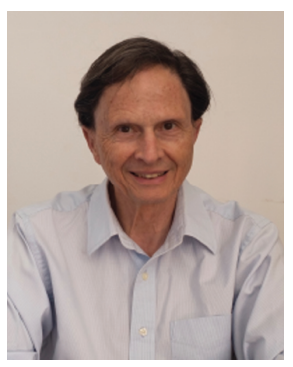

David L. Heymann, MD

Professor, Infectious Disease Epidemiology, London School of Hygiene and Tropical Medicine Distinguished Fellow, Chatham House London 